\title{
Efferent Pathways Modulate Hyperactivity in Inferior Colliculus
}

\author{
Wilhelmina Henrica A. M. Mulders, ${ }^{1}$ Kumar Seluakumaran, ${ }^{1,2}$ and Donald Robertson ${ }^{1}$ \\ ${ }^{1}$ The Auditory Laboratory, Discipline of Physiology, School of Biomedical, Biomolecular, and Chemical Sciences, The University of Western Australia, \\ Crawley, Western Australia 6009, Australia, and 2Department of Physiology, Faculty of Medicine, University of Malaya, 50603 Kuala Lumpur, Malaysia
}

\begin{abstract}
Animal models have demonstrated that mild hearing loss caused by acoustic trauma results in spontaneous hyperactivity in the central auditory pathways. This hyperactivity has been hypothesized to be involved in the generation of tinnitus, a phantom auditory sensation. We have recently shown that such hyperactivity, recorded in the inferior colliculus, is still dependent on cochlear neural output for some time after recovery (up to 6 weeks). We have now studied the capacity of an intrinsic efferent system, i.e., the olivocochlear system, to alter hyperactivity. This system is known to modulate cochlear neural output. Anesthetized guinea pigs were exposed to a loud sound and after 2 or 3 weeks of recovery, single-neuron recordings in inferior colliculus were made to confirm hyperactivity. Olivocochlear axons were electrically stimulated and effects on cochlear neural output and on highly spontaneous neurons in inferior colliculus were assessed. Olivocochlear stimulation suppressed spontaneous hyperactivity in the inferior colliculus. This result is in agreement with our earlier finding that hyperactivity can be modulated by altering cochlear neural output. Interestingly, the central suppression was generally much larger and longer lasting than reported previously for primary afferents. Blockade of the intracochlear effects of olivocochlear system activation eliminated some but not all of the effects observed on spontaneous activity, suggesting also a central component to the effects of stimulation. More research is needed to investigate whether these central effects of olivocochlear efferent stimulation are due to central intrinsic circuitry or to coactivation of central efferent collaterals to the cochlear nucleus.
\end{abstract}

\section{Introduction}

It is well established that after lesions of the peripheral auditory receptor, the cochlea, increased spontaneous activity (hyperactivity) develops in central auditory nuclei. This plasticity has been demonstrated in a wide range of animal models, using either mechanically, acoustically, or drug-induced cochlear lesions (Kaltenbach et al., 2000; Seki and Eggermont, 2003; Kaltenbach et al., 2004; Ma et al., 2006; Brozoski et al., 2007; Bauer et al., 2008; Dong et al., 2009, 2010; Mulders and Robertson, 2009). Hyperactivity has been suggested to be involved in the generation of tinnitus, an auditory phantom perception (Brozoski et al., 2002; Kaltenbach et al., 2004; Bauer et al., 2008). This hypothesis is supported by the fact that the hyperactivity seems restricted to tonotopic regions broadly corresponding to the area of hearing loss as shown in cochlear nucleus $(\mathrm{CN})$, the central nucleus of the inferior colliculus (CNIC), and the auditory cortex (Kaltenbach et al., 2000; Komiya and Eggermont, 2000; Seki and Eggermont, 2003; Ma et al., 2006; Dong et al., 2009; Mulders et al., 2009) and the observation in human studies that there is a strong correlation between the tinnitus pitch and the hearing loss frequencies

Received May 5, 2010; accepted June 2, 2010.

This work was supported by grants from the Royal National Institute for Deaf People (United Kingdom), the Medical Health and Research Infrastructure Fund (Western Australia), and The University of Western Australia. We thank Mr. Christo Bester for help with acquisition of sham control data.

Correspondence should be addressed to Wilhelmina Henrica A. M. Mulders, The Auditory Laboratory, Discipline of Physiology, School of Biomedical, Biomolecular, and Chemical Sciences M311, The University of Western Australia, 35 Stirling Highway, Crawley, WA 6009, Australia. E-mail: hmulders@cyllene.uwa.edu.au.

DOI:10.1523/JNEUROSCI.2289-10.2010

Copyright $\odot 2010$ the authors $\quad 0270-6474 / 10 / 309578-10 \$ 15.00 / 0$
(Mühlnickel et al., 1998; Norena et al., 2002; Eggermont and Roberts, 2004).

Although it is generally believed that central hyperactivity is intrinsic to the nuclei involved and is not dependent on increased activity of the auditory nerve (Eggermont and Roberts, 2004), we have recently shown in a guinea pig model of hyperactivity caused by unilateral acoustic trauma that up to 6 weeks later, hyperactivity can be abolished by silencing cochlear activity (Mulders and Robertson, 2009). If indeed hyperactivity is involved in the generation of tinnitus, this finding may open up possible avenues for therapy. In the paper by Mulders and Robertson (2009), the methods used for silencing cochlear output were either irreversible, causing complete deafness (cochlear ablation), or artificial (cochlear perfusion with kainate), which may provide proof of principle but would be unsuitable for clinical application.

It is of interest to know whether intrinsic mechanisms that have the capacity to modulate cochlear activity, for example, the olivocochlear system, would also cause modulation of hyperactivity. Activation of the olivocochlear system, which originates in the brainstem and terminates in the cochlea (Warr and Guinan, 1979; White and Warr, 1983) and CN (Benson and Brown, 1990; Brown, 1993; Benson et al., 1996), is well known to have a suppressive effect on sound-evoked and spontaneous cochlear neural output (Guinan and Gifford, 1988; Rajan, 1988). Therefore, in the present paper we have investigated the effects of activation of the olivocochlear system on the level of hyperactivity caused by acoustic trauma in CNIC neurons. 


\section{Materials and Methods}

Animals. Twenty-three adult pigmented guinea pigs of both sexes were used, weighing between 317 and $420 \mathrm{~g}$ at the time of acoustic trauma or sham surgery. The experimental protocols conformed to the Code of Practice of the National Health and Medical Research Council of Australia, and were approved by the Animal Ethics Committee of The University of Western Australia.

Acoustic trauma and sham surgery. Animals received a subcutaneous injection of $0.1 \mathrm{ml}$ of atropine sulfate $(0.6 \mathrm{mg} / \mathrm{ml})$, followed by diazepam $(5 \mathrm{mg} / \mathrm{kg}$, i.p.) and Hypnorm $(0.315 \mathrm{mg} / \mathrm{ml}$ fentanyl citrate and $10 \mathrm{mg} / \mathrm{ml}$ fluanisone; $1 \mathrm{ml} / \mathrm{kg}$, i.m.). When deep anesthesia was obtained as assessed by the foot withdrawal reflex, animals were placed on a heating blanket in a soundproof room and mounted in hollow ear bars. A small opening was made in the bulla to place an insulated silver wire on the bony shelf close to the round window. A compound action potential (CAP) audiogram (Johnstone et al., 1979) for the frequency range 4-24 $\mathrm{kHz}$ was used to assess the animals' cochlear sensitivity using a closed sound system. All sound stimuli were presented through a $1 / 2$ inch condenser microphone driven in reverse as a speaker (Bruel and Kjaer, type 4134). Pure tone stimuli were synthesized by a computer equipped with DIGI 96 soundcard connected to an analog/digital interface (ADI-9 DS, RME Intelligent Audio Solution). Sample rate was $96 \mathrm{kHz}$. The interface was driven by a custom-made computer program (Neurosound, MI Lloyd), which was also used to collect single-neuron data. CAP signals were amplified, filtered (100 Hz-3 kHz bandpass) and recorded with a second data acquisition system (Powerlab 4SP, AD Instruments). When cochlear sensitivity was determined to be within the normal range the contralateral ear was blocked with plasticine and the animal was subjected to a continuous pure tone of $10 \mathrm{kHz}$ at $124 \mathrm{~dB}$ SPL for $1 \mathrm{~h}$ (acoustic trauma). After the acoustic trauma the CAP audiogram was again measured, the incision was sutured, and buprenorphine $(0.05 \mathrm{mg} / \mathrm{kg}$, s.c.) was given postoperatively as analgesic. Four animals were not subjected to acoustic trauma and served as sham controls. Survival times ranged from 13 to $28 \mathrm{~d}$.

Surgery for efferent experiments. For single-neuron recordings in the inferior colliculus, anesthesia was induced by an injection with $0.1 \mathrm{ml}$ of atropine followed by an intraperitoneal injection of Nembutal (pentobarbitone sodium, $30 \mathrm{mg} / \mathrm{kg}$ ) and a $0.15 \mathrm{ml}$ intramuscular injection of Hypnorm. The maintenance anesthesia regime consisted of full Hypnorm doses every hour and half doses of Nembutal every $2 \mathrm{~h}$. Animals were placed on a heating blanket in a sound proof room and artificially ventilated on carbogen $\left(95 \% \mathrm{O}_{2}\right.$ and $\left.5 \% \mathrm{CO}_{2}\right)$. Animals were paralyzed with $0.1 \mathrm{ml}$ of pancuronium bromide $(2 \mathrm{mg} / \mathrm{ml}$, i.m.). The electrocardiogram was continuously monitored and heart rate never increased over preparalysis levels at any stage of the experiments. At the end of the experiments, animals were killed with $0.3 \mathrm{ml}$ of Lethabarb (sodium pentobarbitone $325 \mathrm{mg} / \mathrm{ml}$, Virbac Australia). After mounting the animals in hollow ear bars, the left cochlea was exposed and an insulated silver wire was placed on the round window to record another CAP audiogram for the frequency range $4-24 \mathrm{kHz}$.

After a craniotomy exposing the cerebellum and the caudal part of the visual cortex, the cerebellum overlying the floor of the IVth ventricle was aspirated. This enabled placement under visual control of the stimulating electrodes on the olivocochlear bundle (OCB) (platinum-iridium concentric bipolar electrodes with a tip diameter between 3 and $4 \mu \mathrm{m}$, World Precision Instruments, connected to an isolated stimulator output, AM Systems Model 2100). To keep the stimulating current necessary to evoke a large OCB effect as low as possible and to minimize the chance of stimulating the dorsal acoustic stria, the stimulating electrodes need to be in very close proximity to the decussation of the OC fibers. To achieve this the stimulating electrodes were placed on the midline and the point was determined where the threshold current to evoke a facial twitch by single shocks was lowest (Seluakumaran et al., 2008). The animals were then paralyzed and proper placement of the stimulating electrodes on the OCB was confirmed by measuring the suppression of the CAP and increase in cochlear microphonic (CM) receptor potential after electrical stimulation using trains of biphasic current pulses ( $100 \mathrm{~ms}$ duration, 0.1 ms pulses, $300 \mathrm{~Hz}$, repetition interval 1/s). To determine the magnitude

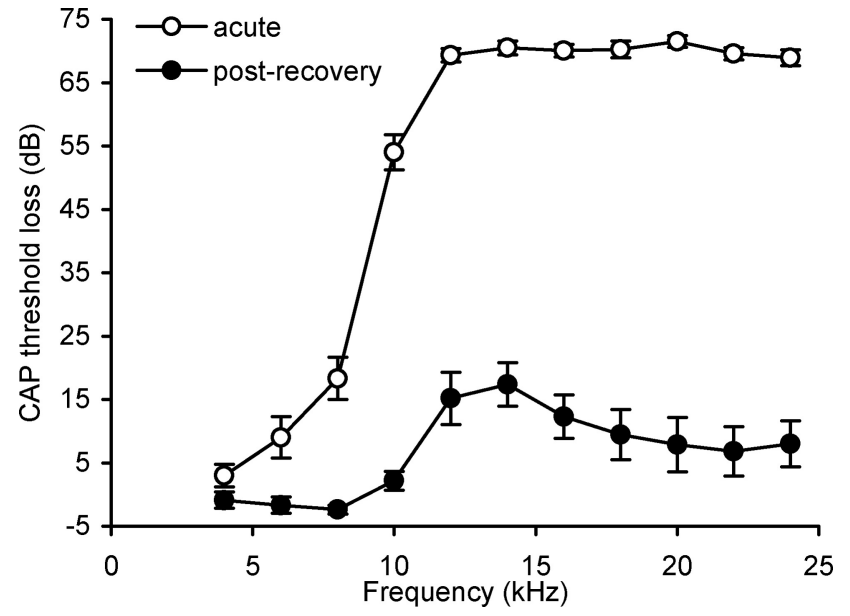

Figure 1. Loss of cochlear sensitivity measured as CAP threshold change recorded in the cochlea after acute acoustic trauma (open circles; $n=16$ ) and after recovery from acoustic trauma (black circles; $n=16$ ). Excluded from this figure are three animals in which only the audiogram after recovery was measured. Data are mean \pm SEM.

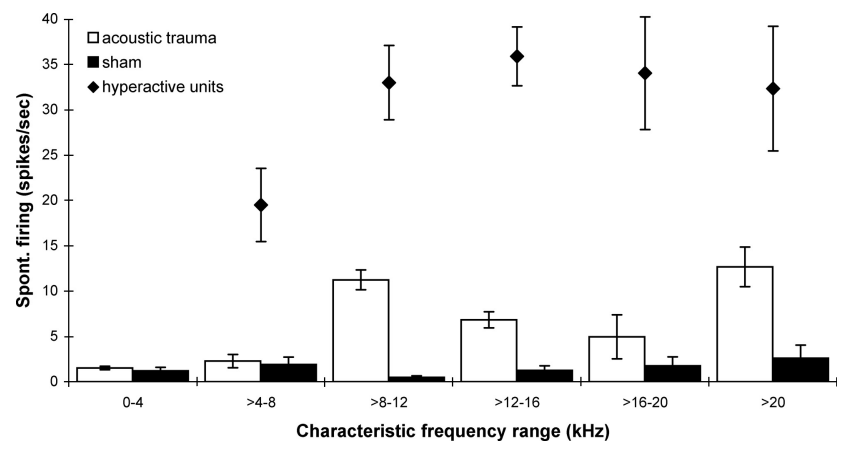

Figure 2. Averaged spontaneous firing rates per CF range in CNIC neurons in sham operated animals (black bars, $n=4$ ) and in animals 2 weeks after acoustic trauma [open bars, $n=5$, data taken from Mulders and Robertson (2009)]. Solid diamonds show averaged spontaneous firing rates of neurons selected for investigation of $O C B$ effects. All data are mean $\pm S E M$.

of the OC-induced suppression, the CAP amplitude after OCB stimulation was matched to the CAP amplitude in response to a tone of a lower intensity. The difference in sound intensity needed to match the amplitudes was used as a measure of the strength of the OC effect (Desmedt, 1962). OCB effects were measured at $10 \mathrm{kHz}$, except when the audiogram showed a threshold loss at this frequency. In these instances, the effect of OCB stimulation was determined at $8 \mathrm{kHz}$. OCB effects measured in this study, were comparable with published data in normal guinea pigs (Mulders et al., 2002) and ranged from 14 to $20 \mathrm{~dB}$ equivalent suppression with current strengths ranging from 150 to $400 \mu \mathrm{A}$. CM responses were measured in the same manner as the CAP using $1 \mathrm{kHz}$ tones at reasonably high sound levels ranging from 94 to $100 \mathrm{~dB}$ SPL to obtain a smooth CM trace. Effects of OC stimulation on cochlear gross potentials were verified regularly throughout the experiment and the experiment was terminated if effects on cochlear gross potentials could not be detected.

To record extracellular single-neuron responses in the CNIC, glassinsulated tungsten microelectrodes (Merrill and Ainsworth, 1972) were advanced vertically through the visual cortex into the contralateral CNIC using a stepping motor microdrive. Electrode placement in the CNIC ( $\sim 2.5 \mathrm{~mm}$ ventral to the cortical surface) was indicated by the onset of strong sound-driven activity with a short latency and a systematic progression from low to high characteristic frequencies (CFs) with increasing depth. The craniotomy was covered with $5 \%$ agar in saline to improve mechanical stability. When a single unit was isolated, its CF and threshold at CF were determined audiovisually, by continuously varying the frequency and intensity of a pure tone stimulus and estimating the lowest 
intensity that evoked a just-detectable increase in firing rate (Shore et al., 2003; Bleeck et al., 2006; Sayles and Winter, 2008). Audiovisual estimates of neuronal CF using the same software as in the present study have been shown to agree closely with those obtained from response area measurements (Ingham et al., 2006). The spontaneous firing rate was measured for a period of $10 \mathrm{~s}$. During all spontaneous rate measurements the speaker was turned off. This abolished the possibility that the spontaneous activity recorded was driven activity caused by uncontrolled background noise from the sound delivery system.

When baseline spontaneous rate was established the effects of electrical stimulation of the OCB on the neuron's spontaneous rate was measured (OCB parameters as for optimal cochlear effects: $100 \mathrm{~ms}$ duration, $0.1 \mathrm{~ms}$ pulses, $300 \mathrm{~Hz}$, $50-100$ repetitions). Repetition rate of OCB stimulation was $0.2 \mathrm{~s}^{-1}$ for most neurons $(n=$ 63) and $1 \mathrm{~s}^{-1}$ for an additional nine neurons.

Cochlear perfusions. In 10 animals, the efferent stimulation was combined with cochlear perfusions of strychnine to block the intracochlear effects of the OCB stimulation. In these animals, a hole was made in the cochlear apex using a hooked pick. The tip of a glass perfusion pipette was carefully inserted using a micromanipulator through a small hole in the scala tympani wall of the basal cochlear turn. The perfusion pipette contained artificial perilymph (127 mM NaCl, $5 \mathrm{~mm} \mathrm{KCl,} 1 \mathrm{~mm}$ $\mathrm{MgCl}_{2} \cdot 6 \mathrm{H}_{2} \mathrm{O}, 1 \mathrm{~mm} \mathrm{NaH}{ }_{2} \mathrm{PO}_{4} \cdot \mathrm{H}_{2} \mathrm{O}, 12 \mathrm{~mm}$ $\mathrm{NaHCO}_{3}, 11 \mathrm{~mm}$ glucose, and $2 \mathrm{~mm} \mathrm{CaCl}_{2}$ at $\mathrm{pH}$ 7.4) with $20 \mu \mathrm{M}$ strychnine added. Perfusion rate was $2 \mu \mathrm{l} / \mathrm{min}$. To monitor cochlear effects, CAP amplitudes were monitored as before with and without efferent stimulation. The effects of efferent stimulation on the neurons were measured before strychnine perfusion, after block of the peripheral effects as assessed by CAP measurements and after recovery of the peripheral effects to before perfusion levels. Recovery of the cochlear efferent effect from strychnine block took $\sim 30$ min.

CNIC field potentials measurements. To assess the effect of electrical stimulation of the OCB on the CNIC and the potential for current spread to the dorsal acoustic stria, in each animal field potential measurements were performed at different depths in the CNIC and with a range of shock strengths applied to the OCB. These measurements were made using the same microelectrode as used for single-neuron recordings. For each individual neuron it was ascertained that a field potential was not observed at the shock strength used.

\section{Results}

\section{Hearing loss}

Immediately after acoustic trauma the audiogram revealed a large hearing loss from $6 \mathrm{kHz}$ upward, with the largest loss $(\sim 70 \mathrm{~dB})$ from $12 \mathrm{kHz}$ to $24 \mathrm{kHz}$ (Fig. 1). However, after 13-28 d of recovery the hearing loss recovered substantially, showing a restricted hearing loss $(\sim 16 \mathrm{~dB})$ peaking at 12 and $14 \mathrm{kHz}$ (Fig. 1), in agreement with previous studies (Dong et al., 2009; Mulders and Robertson, 2009).

\section{CNIC neurons}

In a previous study (Mulders and Robertson, 2009) it was established that in normal animals $95 \%$ of neurons in the CNIC have a spon- taneous rate $<8$ spikes/s. Figure 2 illustrates the low spontaneous firing rates found in all CF regions for the group of sham operated animals in the present study. These data are compared with the average spontaneous rates in the same CF regions seen 2 weeks after acoustic trauma (data from Mulders and Robertson, 2009). The increased incidence of neurons with a high spontaneous firing rate after acoustic trauma encountered in our experiments is in agreement with other studies (Wang et al., 1996, 2002; Imig and Durham, 2005; Ma et al., 2006; Brozoski et al., 2007; Bauer et al., 2008; Dong et al., 2009; Mulders and Robertson, 2009). In the present study, only neurons with a spontaneous firing rate $>8$ spikes/s were selected for testing the effect of efferent stimulation. The average spontaneous firing rate of the neurons selected is also shown in Figure 2. It is apparent that these firing rates are markedly elevated relative to the sham animals.

The effects of electrical stimulation of the OCB were recorded in a total of 72 CNIC neurons 13-28 d after acoustic trauma. The CFs of these neurons ranged from 4.6 to $32 \mathrm{kHz}$ with an average of $12.9 \pm 0.7 \mathrm{kHz}$ and their spontaneous rate ranged from 9.4 to $92.4 \mathrm{spikes} / \mathrm{s}$ with an average of $31.2 \pm 2.3 \mathrm{spikes} / \mathrm{s}$. In 44 of these neurons, only effects of efferent stimulation were assessed (CF 

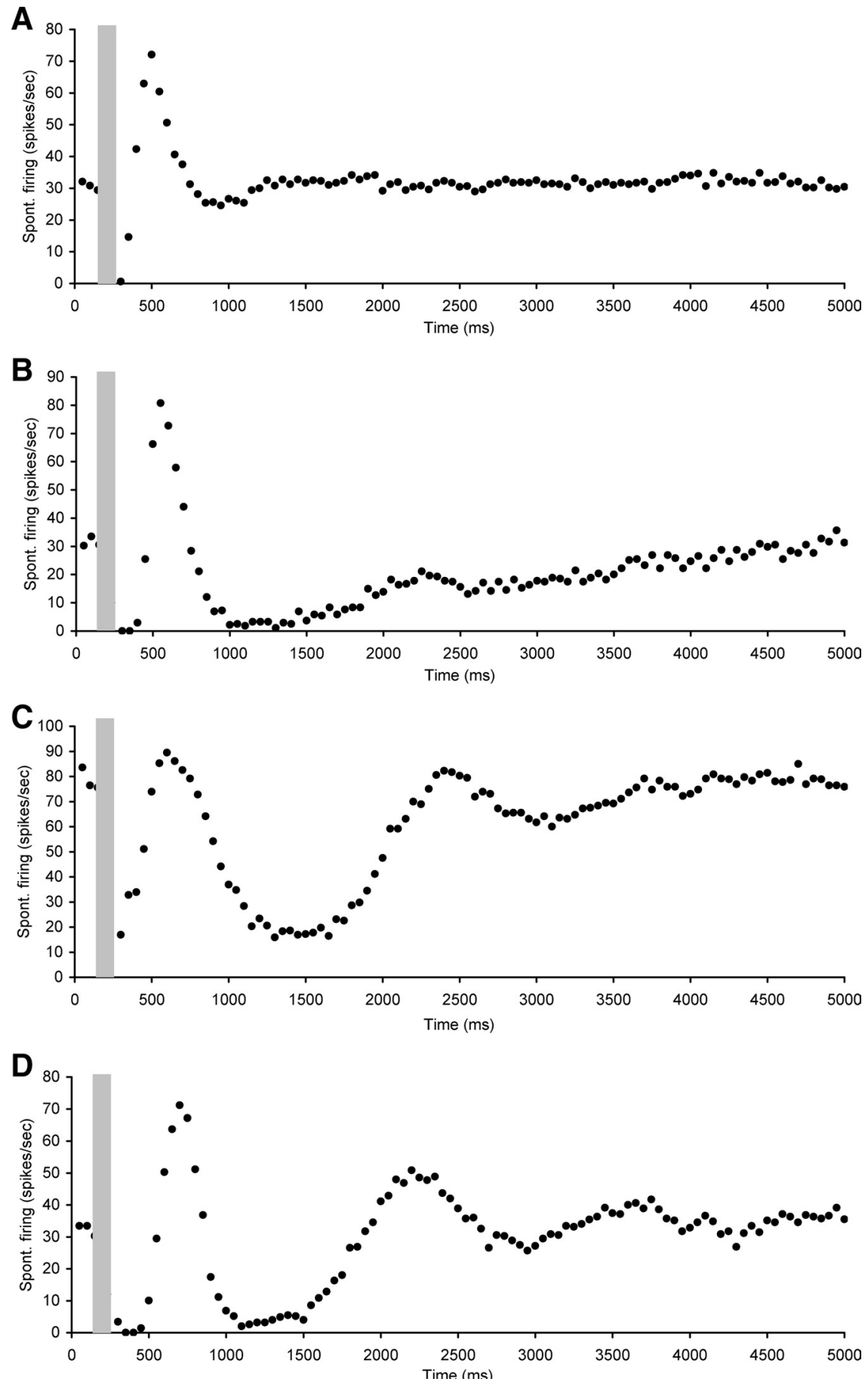

Figure 4. Scatter plots of spontaneous firing of hyperactive CNIC neurons with electrical stimulation of the OCB (gray bar), showing examples of short or nondetectable (ranging from 0 to $450 \mathrm{~ms}$ ) suppression of spontaneous rate followed by more complex changes. $A$, Neuron CF $21.2 \mathrm{kHz}$, threshold $21 \mathrm{~dB}$ SPL. B, Neuron CF $10.9 \mathrm{kHz}$, threshold $29 \mathrm{~dB}$ SPL. C, Neuron CF $18.3 \mathrm{kHz}$, threshold $75 \mathrm{~dB}$ SPL. D, Neuron CF $9.7 \mathrm{kHz}$, threshold $28 \mathrm{~dB}$ SPL. Stimulation parameters: 100 ms duration, 0.1 ms pulses, $300 \mathrm{~Hz}$. Stimulation strength in $\boldsymbol{A}$ was $350 \mu \mathrm{A}$, in $\boldsymbol{B}$ and $\mathbf{C} 250 \mu \mathrm{A}$, and in $\boldsymbol{D} 400 \mu \mathrm{A}$.

Effects of efferent stimulation without strychnine application

In each animal, the level of efferent (OCB) stimulation was adjusted to result in a near-maximal effect on the CAP amplitude recorded from the cochlea. Stimulation levels ranged from 150 to $400 \mu \mathrm{A}$. In all animals, the suppression of CAP amplitude was equivalent to a decrease in intensity of between 14 and $20 \mathrm{~dB}$ SPL. OCB activation was further confirmed by observing an increase in CM amplitude.

Electrical stimulation of the OCB resulted in marked changes in the level of spontaneous firing rates of hyperactive CNIC neurons. The effects were diverse but could be divided into four main categories. The first category comprised neurons $(n=20)$ that showed a short-lasting (ranging from 100 to $400 \mathrm{~ms}$ ) but complete suppression of spontaneous rate followed by a return to baseline spontaneous rate levels (Fig. 3). The mean CF of neurons in this category was $11.2 \pm 1.3 \mathrm{kHz}$ (ranging between 6 and $28 \mathrm{kHz}$ ) and mean spontaneous firing rate was $22.8 \pm 2.7$ spikes/s (ranging between 9.4 and 50.7 spikes/s).

The second category comprised neurons $(n=45)$ that showed a short $(50-450 \mathrm{~ms}$ duration) suppression of spontaneous rate followed by more complex changes. These changes included sharp overshoots after the initial suppression followed by a return to baseline levels which could be either fast or slow, sharp overshoots followed by another period of suppression before return to baseline or oscillatory patterns (Fig. 4). The mean CF of neurons in this category was $13.6 \pm 0.8 \mathrm{kHz}$ (ranging between 4.6 and $32 \mathrm{kHz}$ ) and their mean spontaneous firing rate was $34.3 \pm 3.2$ spikes/s (ranging between 9.5 and 92.4 spikes/s).

The third category consisted of five neurons that showed a long suppression after stimulation (ranging from 500 to $2550 \mathrm{~ms}$ ) with either some oscillation visible after the suppression or a slow return to baseline levels (Fig. 5). The mean CF of neurons in this category was $12.3 \pm 1.8$ $\mathrm{kHz}$ (ranging between 9 and $18.6 \mathrm{kHz}$ ) with a mean spontaneous firing rate of $35.8 \pm 6.0$ spikes/s (ranging between 19.6 and 51.3 spikes/s).

The fourth category (examples not shown) consisted of two neurons in which OCB stimulation had no effect on spontaneous rate. The $\mathrm{CF}$ of these neurons was

range between 5.1 and $32 \mathrm{kHz}$, mean $12.9 \pm 0.8 \mathrm{kHz}$, spontaneous rate range between 9.5 and 84.6 , mean $32.9 \pm 2.8$ ), but in 28 neurons efferent effects were recorded before and after block of medial olivocochlear peripheral effects by cochlear strychnine perfusions (CF range between 4.6 and $28 \mathrm{kHz}$, mean $12.8 \pm 1 \mathrm{kHz}$, spontaneous rate range between 9.4 and 92.4, mean $28.6 \pm 3.4$ ).
17.4 and $16.7 \mathrm{kHz}$ with spontaneous rates of 22.5 and 34.7 spikes/s, respectively. Nonetheless, there was a significant effect of OCB activation in the periphery ( $15 \mathrm{~dB}$ equivalent at $10 \mathrm{kHz}$ and $\sim 6 \mathrm{~dB}$ equivalent at $17 \mathrm{kHz}$ ).

There were no statistically significant differences regarding $\mathrm{CF}$ and spontaneous firing rate between the four categories (Kruskall-Wallis test). 


\section{Effects of efferent stimulation with} strychnine application

Twenty-eight neurons were held long enough to obtain measurements of spontaneous activity before and after intracochlear strychnine perfusion. Fifteen of these neurons were selected for analysis. Selection criteria were a total loss of peripheral inhibition with electrical stimulation of the OCB as established with CAP measurements and no evidence of a field potential in CNIC with electrical stimulation of the OCB at the current strength used while measuring the effects on spontaneous activity.

In 8 of these 15 neurons, the initial suppression (before application of strychnine) caused by electrical stimulation of the OCB (varying in these neurons from 150 to $600 \mathrm{~ms}$ ) was completely abolished by strychnine perfusion. Two of these neurons were of category 1 , in which only suppression was observed with OCB activation, and the strychnine perfusion therefore abolished all effects on these neurons (Fig. 6A). The remaining six neurons belonged to category 2 (short suppression followed by complex changes). In all these neurons, the short suppression was abolished but other more complex changes could still be observed after intracochlear strychnine perfusion. Figure $6 B$ illustrates an example of one of the category 2 neurons showing that intracochlear strychnine perfusion resulted in an absence of the immediate suppression following OCB stimulation. However, an immediate overshoot followed by a small suppression was still present. Figure $6 C$ shows another example of a category 2 neuron in which OCB stimulation after intracochlear strychnine perfusion led to late suppression followed by some very small oscillations.

In 4 of the 15 neurons, the immediate suppression observed after OCB stimulation was not completely abolished by cochlear strychnine perfusion, but its duration was reduced from 250, 500, 650 , or $1350 \mathrm{~ms}$ before strychnine to $200,300,150$, and $600 \mathrm{~ms}$ after strychnine, respectively (Fig. $7 A-D$ ). Figure $7 C$ shows a neuron that at first sight (before strychnine perfusion) seems to show some suppression followed by a large long-lasting overshoot before returning to baseline. However, in this figure panel the neuron's spontaneous rate without electrical stimulation or strychnine perfusion is also indicated as a dotted line. This illustrates that in this particular neuron the OCB activation causes both an immediate suppression, but also a late component suppression (starting $\sim 2.5 \mathrm{~s}$ after electrical stimulation) which lasts beyond the $5 \mathrm{~s}$ trial, decreasing the "prestimulation" spontaneous rate value. In between the early and late suppression there was also a small excitatory effect. Strychnine perfusion in the cochlea seemed to eliminate or reduce the early suppression, but still shows some small excitatory effect and a reduced late suppression. Figure $7 D$ shows a neuron with long-lasting initial suppression before strychnine perfusion. Cochlear perfusion with strychnine eliminated the immediate suppression but a later inhibitory effect was still apparent, starting $\sim 300 \mathrm{~ms}$ after stimulation.

The final three neurons are shown in Figure 8. One of these neurons (Fig. 8A) showed no immediate suppression with electrical activation of the $\mathrm{OCB}$, even though the $\mathrm{OCB}$ effect in the cochlea was equivalent to $15 \mathrm{~dB}$ at $8 \mathrm{kHz}$. Instead there was an immediate overshoot followed by suppression and some oscillation. Strychnine perfusion did not change these effects. Finally, there were two neurons in which strychnine perfusion in the cochlea had no effect on the suppression observed (200 and 250 $\mathrm{ms}$ ), but in both instances decreased the overshoot that followed the suppression while leaving the other later effects unchanged (Fig. $8 B, C$ ).

In eight neurons, the effects of OCB stimulation were observed before and immediately after strychnine blockade as well as after recovery. Figure 9 shows four examples, illustrating that the effects were highly reversible and repeatable.

\section{Discussion}

The present data demonstrate for the first time that activation of the intrinsic efferent system, the OC system, can alter the abnormally high levels of spontaneous activity of CNIC neurons that are present 2-4 weeks after acoustic trauma. Some of the effects of OCB stimulation were caused by intracochlear action, but other effects must be the result of direct effect of the stimulation on central pathways since they remained after intracochlear blockade of the receptors of the medial OC system. The relationship between these OCB effects on spontaneous hyperactivity after acoustic trauma and the effects on spontaneous activity in normal animals is unknown. In normal animals with the anesthetic regime used in the present study spontaneous firing rates of CNIC neurons are so low (Torterolo et al., 2002; Mulders and Robertson, 2009) that any OCB effects are difficult to quantify.

The observation that the increased spontaneous activity of CNIC neurons can be modulated by OCB stimulation is consistent with our recent findings that silencing the auditory nerve suppresses the high spontaneous activity of CNIC neurons up to 6 weeks after acoustic trauma (Mulders and Robertson, 2009), and the well described effects of OCB stimulation on auditory 

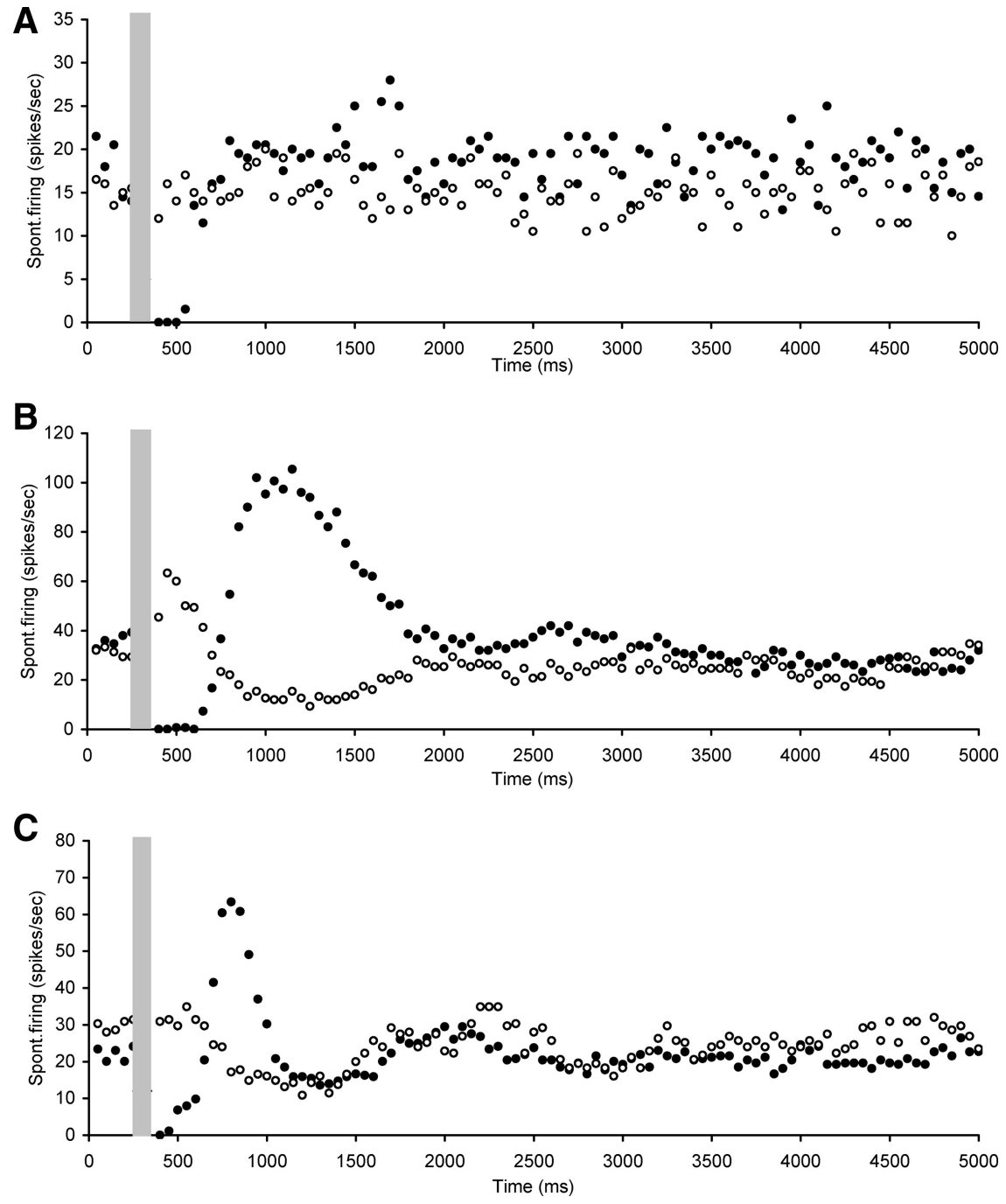

Figure 6. Scatter plots of spontaneous firing of hyperactive CNIC neurons with electrical stimulation of the OCB (gray bar), recorded both before (dark circles) and after (open circles) strychnine perfusion in the cochlea. Illustrations of neurons where the immediate suppression was abolished $(\boldsymbol{A}-\boldsymbol{C})$, but sometimes later effects remained $(\boldsymbol{B}, \boldsymbol{C})$. $\boldsymbol{A}$, Neuron $(F) .8 \mathrm{kHz}$, threshold $20 \mathrm{~dB}$ SPL. $\boldsymbol{B}$, Neuron CF $9.2 \mathrm{kHz}$, threshold $21 \mathrm{~dB}$ SPL. C, Neuron CF $14.5 \mathrm{kHz}$, threshold $22 \mathrm{~dB}$ SPL. Stimulation parameters: $100 \mathrm{~ms}$ duration, $0.1 \mathrm{~ms}$ pulses, $300 \mathrm{~Hz}$. Stimulation strength in $\boldsymbol{A}$ and $\boldsymbol{B}$ was $300 \mu \mathrm{A}$ and in $\boldsymbol{C} 150 \mu \mathrm{A}$.

afferent firing. Electrical stimulation of the OCB at the floor of the IVth ventricle is thought to stimulate the medial OC system (Gifford and Guinan, 1987), which terminates onto the cochlear outer hair cells (Liberman and Brown, 1986; Dallos et al., 1997). In addition to modulating the electro-mechanical gain of the cochlea (Dallos et al., 1997), medial system activation also results in a reduction of spontaneous firing of auditory afferents (Wiederhold and Kiang, 1970; Guinan and Gifford, 1988). This is most likely caused by a decrease in the endocochlear potential, arising from a shunt in current through the $\mathrm{OHC}$ when the medial system is activated (Housley and Ashmore, 1991; Blanchet et al., 2000). The reduced endocochlear potential causes hyperpolarization of the inner hair cells and a reduction of the spontaneous neurotransmitter release onto the auditory afferent fibers, reducing spontaneous firing of the afferents (Brown and Nuttall, 1984; Sewell, 1984).

It is noteworthy that the suppression of spontaneous firing rate reported in primary afferents after electrical activation of the OCB is qualitatively different from the suppression shown in the present data. The maximum amount of suppression observed in primary afferents was 50\% (Wiederhold and Kiang, 1970; Guinan and Gifford, 1988), whereas in most instances there was a $100 \%$ reduction of spontaneous firing observed in CNIC neurons in the present experiments. Nonetheless, in many neurons a complete elimination of this suppression was produced after blockade of the intracochlear effects of OCB stimulation with strychnine. This indicates that the striking effects of OCB stimulation on central hyperactivity were due to the intracochlear effects of OCB stimulation on the primary afferents. The explanation for the discrepancy in magnitude of suppression is unknown. An earlier study on the effects of OCB stimulation on CNIC neurons in control animals described a similar difference in the magnitude of effect on spontaneous activity (Seluakumaran et al., 2008), whereas in the $\mathrm{CN}$ of control animals the effects of $\mathrm{OCB}$ stimulation on spontaneous activity are small (Mulders et al., 2008). These observations suggest that local intrinsic circuitry between $\mathrm{CN}$ and CNIC is capable of increasing the effect of OCB stimulation on spontaneous activity.

Another notable aspect of the suppression in hyperactive CNIC neurons after OCB stimulation was its duration (up to $2.5 \mathrm{~s}$ after stimulation). The strychnine experiments indicate that at least $450 \mathrm{~ms}$ of suppression can be attributed to intracochlear effects of stimulation. Whether this is a direct translation of long-lasting effects on primary afferents or again due to further modulation by intrinsic circuitry is unknown. Starr and Wernick (1968) recording in CN of normal cats also showed that electrical stimulation of the OCB could result in suppression of spontaneous rate for up to $500 \mathrm{~ms}$ in duration after stimulation ceased. There is no compelling evidence for such long-lasting suppression of primary afferent spontaneous firing by OCB stimulation. Studies on the effects of OCB stimulation on primary afferents in cats describe mainly effects during stimulation (Wiederhold and Kiang, 1970; Guinan and Gifford, 1988). These studies do not describe the precise duration of effects after stimulation ceased, but only describe the effects as disappearing rapidly.

In two neurons, the blockade of intracochlear effects with strychnine perfusion had no effect on the immediate suppression but it did eliminate the overshoot after the suppression. Overshoots have been reported to occur in primary afferent as well after OCB stimulation (Wiederhold and Kiang, 1970; Guinan and Gifford, 1988). Since in the present data the overshoot could be eliminated without an effect on the suppression, this suggests it is not just a rebound of inhibition but rather a late excitatory effect caused by electrical stimulation of the OC system.

When the intracochlear effects of medial OC system were blocked by strychnine, electrical stimulation of the OCB still resulted in a variety of effects on spontaneous rate, including late inhibition and excitation. There are three possible explanations 
for these persistent effects. The first possibility is that some of the effects are caused by activation of the lateral OC system, whose axons run close to the site of stimulation (Brown, 1993; Warr et al., 1997) and which project to the primary afferent dendrites underneath the inner hair cells in the cochlea (Warr et al., 1997). Since the $\alpha 9$ and $\alpha 10$ subunits of the nicotinic acetylcholine receptor are specific for the medial system (Vetter et al., 1999; Lustig, 2006), the blockade by strychnine perfusion would not alter any lateral effects on primary afferents. However, activation of the lateral system by electrical stimulation at the floor of the IVth ventricle has never been confirmed and is considered unlikely in view of the unmyelinated axons of the lateral system (Brown, 1987; Warr et al., 2002).

A second possibility is that the electrical stimulation not only stimulated the medial OC system but also axons projecting out of the $\mathrm{CN}$. These could include contralaterally projecting neurons (Cant and Gaston, 1982; Schofield and Cant, 1996), whose axons run close to the surface of the floor of the IVth ventricle (Arnott et al., 2004; Smith et al., 2005). Stimulation of these axons could cause either orthodromic or antidromic effects in $\mathrm{CN}$ which would flow on to IC (Cant and Benson, 2003). These effects could then be manifested as the excitatory or inhibitory changes observed in the present experiments that remained after strychnine perfusions. It is also possible that the electrical stimulation resulted in unintentional activation of the dorsal acoustic stria, comprised of axons from the dorsal CN projecting to the IC (Smith et al., 2005). However, we placed our stimulating electrodes at the point of the lowest shock threshold to elicit facial twitch (before paralysis), and we have shown previously that this should not result in activation of ascending axons when stimulating current is kept low (Seluakumaran et al., 2008). To minimize the possibility involvement of the dorsal acoustic stria, we excluded neurons from analysis when a field potential could be detected in IC.

A third possibility is that the medial OC system provides direct input to $\mathrm{CN}$ neurons. Medial OC neurons are known to have collaterals projecting to the $\mathrm{CN}$ (Winter et al., 1989; Benson and Brown, 1990; Benson and Potashner, 1990; Brown, 1993; Benson et al., 1996; Horváth et al., 2000), and we have previously shown direct excitatory effects of these collaterals on $\mathrm{CN}$ neurons, in particular onset chopper neurons (Mulders et al., 2002, 2003, 2007, 2009). These neurons are thought to provide wide band inhibition to other CN neurons (Verhey et al., 2003; Arnott et al., 2004; Neuert et al., 2004) and could be responsible for the modula-
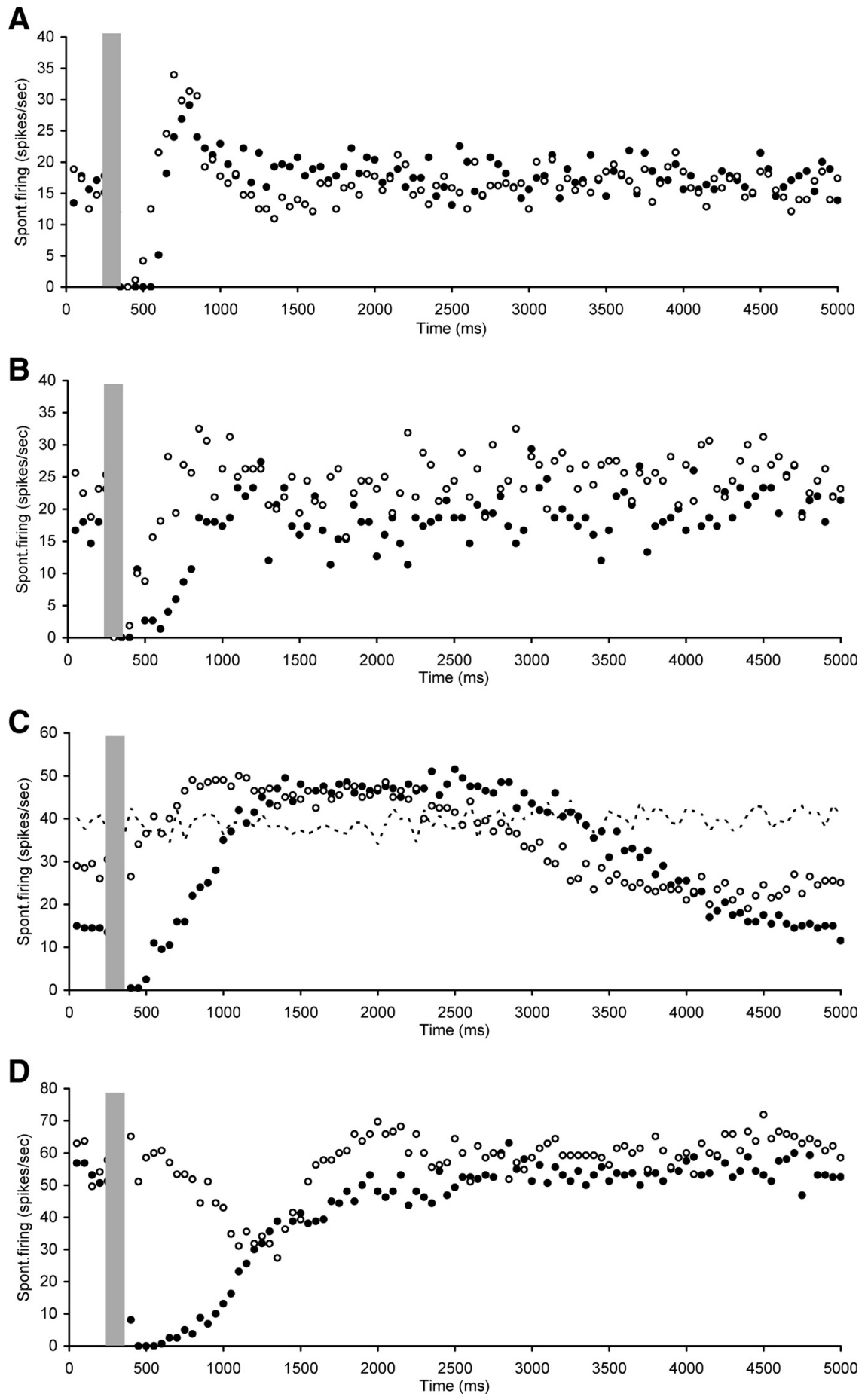

Figure 7. Scatter plots of spontaneous firing of hyperactive CNIC neurons with electrical stimulation of the OCB (gray bar), recorded both before (dark circles) and after (open circles) strychnine perfusion in the cochlea. Illustrations of neurons in which the immediate suppression observed after $O C B$ stimulation was not completely abolished by cochlear strychnine perfusion but its duration was reduced. In Calso indicated is the spontaneous firing rate without $O C B$ stimulation or strychnine perfusion (dotted line). $A$, Neuron CF $8.5 \mathrm{kHz}$, threshold 43 dB SPL. B, Neuron CF 9.2 kHz, threshold $67 \mathrm{~dB}$ SPL. C, Neuron nonresponsive to sound. $\boldsymbol{D}$, Neuron CF $9 \mathrm{kHz}$, threshold $61 \mathrm{~dB}$ SPL. Stimulation parameters: 100 ms duration, 0.1 ms pulses, $300 \mathrm{~Hz}$. Stimulation strength in $\boldsymbol{A}$ and $\boldsymbol{D}$ was $250 \mu A$ and in $\boldsymbol{B}$ and $\boldsymbol{C} 300 \mu A$. tion of spontaneous activity remaining after cochlear strychnine. Further investigations are required to determine the exact cause of the extensive effects on spontaneous rate when the peripheral effects of the OC system are blocked.

Our present results clearly indicate a strong effect of stimulation of the medial OC system on hyperactivity caused by acoustic trauma. This demonstration that an intrinsic control system can 

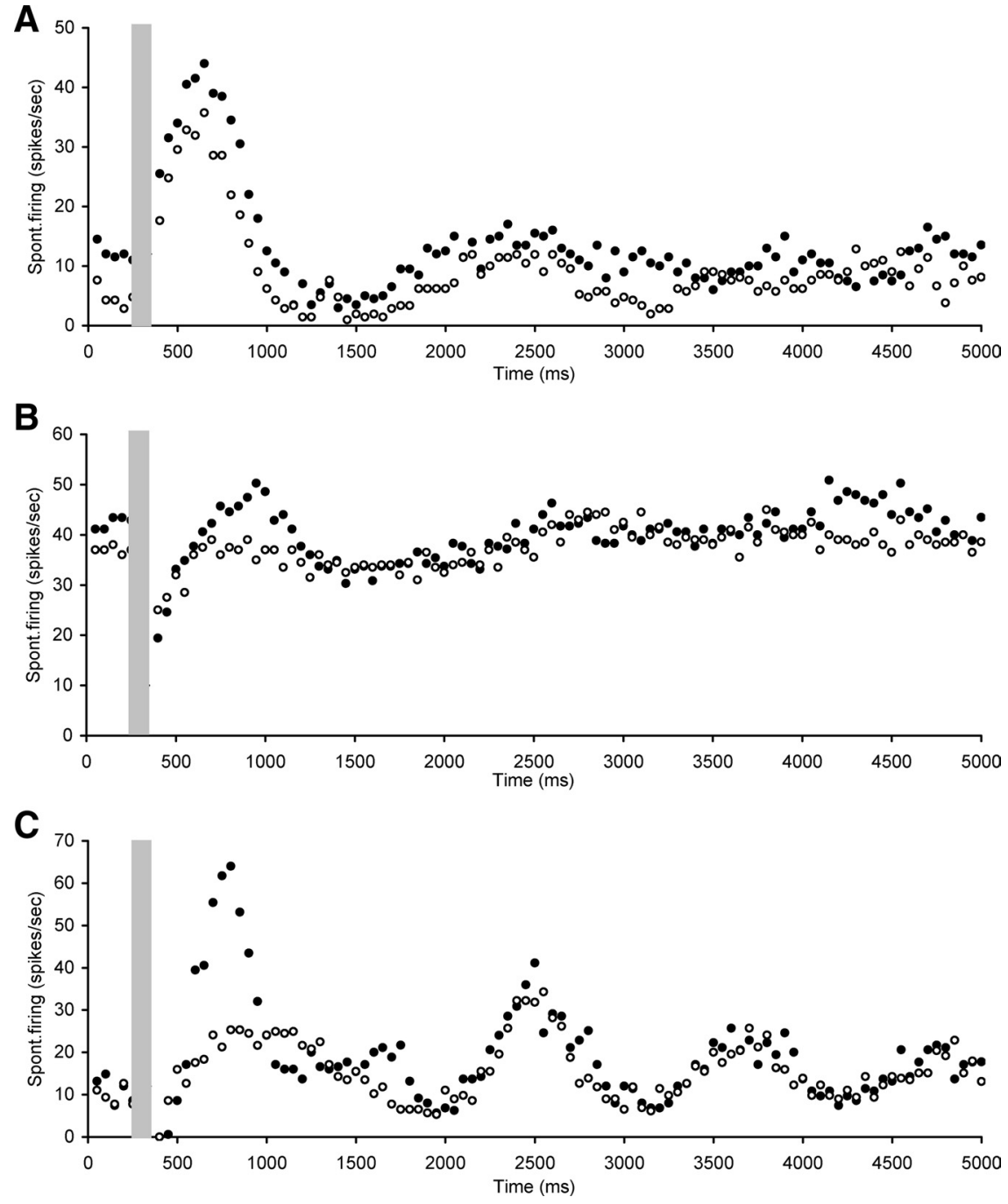

Figure 8. Scatter plots of spontaneous firing of hyperactive CNIC neurons with electrical stimulation of the OCB (gray bar), recorded both before (dark circles) and after (open circles) strychnine perfusion in the cochlea. $A$, Illustration of neuron in which strychnine perfusion did not change effects of $O C B$ stimulation. $B, C$, Two neurons in which strychnine perfusion in the cochlea did not affect the suppression, but did decrease the following overshoot. $A$, Neuron CF $22.9 \mathrm{kHz}$, threshold $44 \mathrm{~dB}$ SPL. $B$, Neuron CF 18 kHz, threshold $66 \mathrm{~dB}$ SPL. C, Neuron CF $16.8 \mathrm{kHz}$, threshold $36 \mathrm{dBSPL}$. Stimulation parameters: 100 ms duration, $0.1 \mathrm{~ms}$ pulses, 300 $\mathrm{Hz}$. Stimulation strength in $\boldsymbol{A}$ was $250 \mu \mathrm{A}$, in $\boldsymbol{B} 350 \mu \mathrm{A}$, and in $\mathbf{C} 150 \mu \mathrm{A}$.

modify maladaptive plastic phenomena in the auditory pathway, could have important clinical implications. If spontaneous hyperactivity is indeed involved in the generation of tinnitus (Brozoski et al., 2002; Kaltenbach et al., 2004; Bauer et al., 2008), then our results could indicate a beneficial effect of OC system activation on tinnitus. Our observations that the suppressive effects on spontaneous activity lasted after the stimulation had ceased, is consistent with a role for the OC system in residual inhibition, a temporary reduction of tinnitus experienced in tinnitus patients that persists for a few seconds after masking sounds are turned off (Vernon and Meikle, 2003; Roberts et al., 2008). Furthermore, activation of the OC system could be a contributory mechanism to the often beneficial effects of masking sounds on the perception of tinnitus (Jastreboff, 2007; Lugli et al., 2009), since the OC system itself can be activated by sound (Robertson and Gummer, 1985; Robertson and Winter, 1988; Thompson and Thompson, 1991; Brown et al., 2003; Lugli et al., 2009). Finally, focal and specific pharmacological manipulation of the peripheral action of the OC system might offer therapeutic possibilities for the treatment of tinnitus without the complications of unwanted central side effects.

\section{References}

Arnott RH, Wallace MN, Shackleton TM, Palmer AR (2004) Onset neurones in the anteroventral cochlear nucleus project to the dorsal cochlear nucleus. J Assoc Res Otolaryngol 5:153-170.

Bauer CA, Turner JG, Caspary DM, Myers KS, Brozoski TJ (2008) Tinnitus and inferior colliculus activity in chinchillas related to three distinct patterns of cochlear trauma. J Neurosci Res 86:2564-2578.

Benson CG, Potashner SJ (1990) Retrograde transport of $[3 \mathrm{H}]$ glycine from the cochlear nucleus to the superior olive in the guinea pig. J Comp Neurol 296:415-426.

Benson TE, Brown MC (1990) Synapses formed by olivocochlear axon branches in the mouse cochlear nucleus. J Comp Neurol 295:52-70.

Benson TE, Berglund AM, Brown MC (1996) Synaptic input to cochlear nucleus dendrites that receive medial olivocochlear synapses. J Comp Neurol 365:27-41.

Blanchet C, Erostegui C, Sugasawa M, Dulon D (2000) Gentamicin blocks ACh-evoked K+ current in guinea-pig outer hair cells by impairing $\mathrm{Ca} 2+$ entry at the cholinergic receptor. J Physiol 525:641-654.

Bleeck S, Sayles M, Ingham NJ, Winter IM (2006) The time course of recovery from suppression and facilitation from single units in the mammalian cochlear nucleus. Hear Res 212:176-184.

Brown MC (1987) Morphology of labeled efferent fibers in the guinea pig cochlea. J Comp Neurol 260:605-618.

Brown MC (1993) Fiber pathways and branching patterns of biocytin-labeled olivocochlear neurons in the mouse brainstem. J Comp Neurol 337:600-613.

Brown MC, Nuttall AL (1984) Efferent control of cochlear inner hair cell responses in the guinea-pig. J Physiol 354:625-646.

Brown MC, de Venecia RK, Guinan JJ Jr (2003) Responses of medial olivocochlear neurons. Specifying the central pathways of the medial olivocochlear reflex. Exp Brain Res 153:491-498.

Brozoski TJ, Bauer CA, Caspary DM (2002) Elevated fusiform cell activity in the dorsal cochlear nucleus of chinchillas with psychophysical evidence of tinnitus. J Neurosci 22:2383-2390.

Brozoski TJ, Ciobanu L, Bauer CA (2007) Central neural activity in rats with tinnitus evaluated with manganese-enhanced magnetic resonance imaging (MEMRI). Hear Res 228:168-179.

Cant NB, Benson CG (2003) Parallel auditory pathways: projection patterns of the different neuronal populations in the dorsal and ventral cochlear nuclei. Brain Res Bull 60:457-474.

Cant NB, Gaston KC (1982) Pathways connecting the right and left cochlear nuclei. J Comp Neurol 212:313-326.

Dallos P, He DZ, Lin X, Sziklai I, Mehta S, Evans BN (1997) Acetylcholine, outer hair cell electromotility, and the cochlear amplifier. J Neurosci 17:2212-2226.

Desmedt J (1962) Auditory-evoked potentials from cochlea to cortex as influenced by activation of the efferent olivocochlear bundle. J Acoust Soc Am 34:1478-1496.

Dong S, Mulders WH, Rodger J, Robertson D (2009) Changes in neuronal activity and gene expression in guinea-pig auditory brainstem after unilateral partial hearing loss. Neuroscience 159:1164-1174. 
Dong S, Mulders WHAM, Rodger J, Woo S, Robertson D (2010) Acoustic trauma evokes hyperactivity and changes in gene expression in guinea pig auditory brainstem. Eur J Neurosci 31:1616-1628.

Eggermont JJ, Roberts LE (2004) The neuroscience of tinnitus. Trends Neurosci 27: 676-682.

Gifford ML, Guinan JJ Jr (1987) Effects of electrical stimulation of medial olivocochlear neurons on ipsilateral and contralateral cochlear responses. Hear Res 29:179-194.

Guinan JJ Jr, Gifford ML (1988) Effects of electrical stimulation of efferent olivocochlear neurons on cat auditory-nerve fibers. II. Spontaneous rate. Hear Res 33:115-127.

Horváth M, Kraus KS, Illing RB (2000) Olivocochlear neurons sending axon collaterals into the ventral cochlear nucleus of the rat. J Comp Neurol 422:95-105.

Housley GD, Ashmore JF (1991) Direct measurement of the action of acetylcholine on isolated outer hair cells of the guinea pig cochlea. Proc Biol Sci 244:161-167.

Imig TJ, Durham D (2005) Effect of unilateral noise exposure on the tonotopic distribution of spontaneous activity in the cochlear nucleus and inferior colliculus in the cortically intact and decorticate rat. J Comp Neurol 490:391-413.

Ingham NJ, Bleeck S, Winter IM (2006) Contralateral inhibitory and excitatory frequency response maps in the mammalian cochlear nucleus. Eur J Neurosci 24:2515-2529.

Jastreboff MM (2007) Sound therapies for tinnitus management. Prog Brain Res 166:435-440.

Johnstone JR, Alder VA, Johnstone BM, Robertson D, Yates GK (1979) Cochlear action potential threshold and single unit thresholds. J Acoust Soc Am 65:254-257.

Kaltenbach JA, Zhang J, Afman CE (2000) Plasticity of spontaneous neural activity in the dorsal cochlear nucleus after intense sound exposure. Hear Res 147:282-292.

Kaltenbach JA, Zacharek MA, Zhang J, Frederick S (2004) Activity in the dorsal cochlear nucleus of hamsters previously tested for tinnitus following intense tone exposure. Neurosci Lett 355:121-125.

Komiya H, Eggermont JJ (2000) Spontaneous firing activity of cortical neurons in adult cats with reorganized tonotopic map following pure-tone trauma. Acta Otolaryngol 120:750-756.

Liberman MC, Brown MC (1986) Physiology and anatomy of single olivocochlear neurons in the cat. Hear Res 24:17-36.

Lugli M, Romani R, Ponzi S, Bacciu S, Parmigiani S (2009) The windowed sound therapy: a new empirical approach for an effectiv personalized treatment of tinnitus. Int Tinnitus J 15:51-61.

Lustig LR (2006) Nicotinic acetylcholine receptor structure and function in the efferent auditory system. Anat Rec A Discov Mol Cell Evol Biol 288:424-434.

Ma WL, Hidaka H, May BJ (2006) Spontaneous activity in the inferior colliculus of $\mathrm{CBA} / \mathrm{J}$ mice after manipulations that induce tinnitus. Hear Res 212:9-21.

Merrill EG, Ainsworth A (1972) Glass-coated platinum-plated tungsten microelectrodes. Med Biol Eng 10:662-672.

Mühlnickel W, Elbert T, Taub E, Flor H (1998) Reorganization of auditory cortex in tinnitus. Proc Natl Acad Sci U S A 95:10340-10343.

Mulders WH, Robertson D (2009) Hyperactivity in the auditory midbrain after
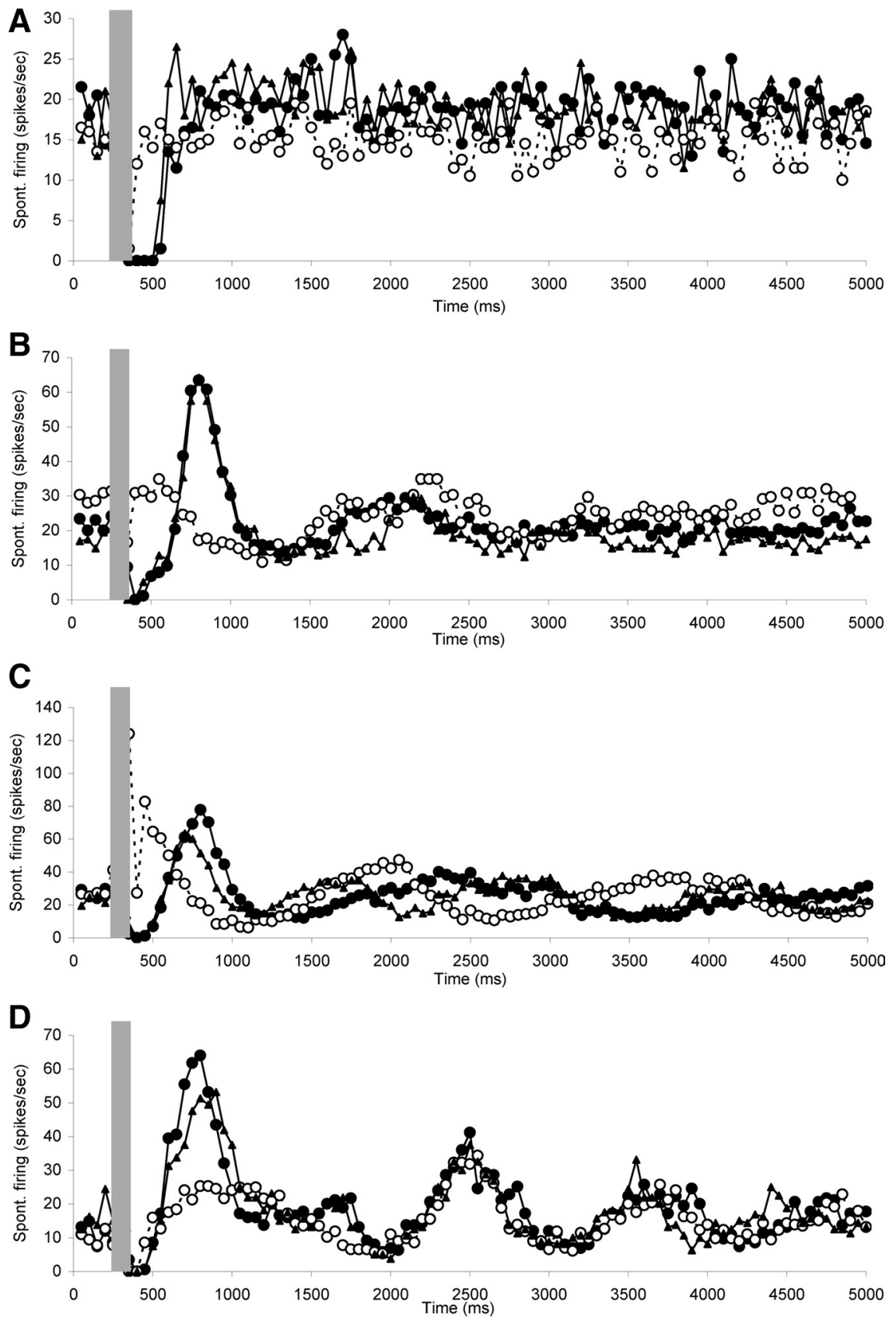

Figure 9. Scatter plots of spontaneous firing of hyperactive CNIC neurons with electrical stimulation of the OCB (gray bar), recorded before (dark circles) and after (open circles) strychnine perfusion in the cochlea, as well as after recovery from the strychnine effects (dark triangles). Note reversibility of the strychnine effects and the repeatability of all components of the OCB $23 \mathrm{~dB}$ SPL. C, Neuron CF $13.9 \mathrm{kHz}$, threshold $39 \mathrm{dBSPL}$. D, Neuron CF $16.8 \mathrm{kHz}$, threshold $36 \mathrm{~dB}$ SPL. Stimulation parameters: $100 \mathrm{~ms}$ duration, $0.1 \mathrm{~ms}$ pulses, $300 \mathrm{~Hz}$. Stimulation strength in $\boldsymbol{A}$ was $250 \mu \mathrm{A}$ and in $\boldsymbol{B}-\boldsymbol{D} 150 \mu \mathrm{A}$.

acoustic trauma: dependence on cochlear activity. Neuroscience 164:733-746.

Mulders WH, Winter IM, Robertson D (2002) Dual action of olivocochlear collaterals in the guinea pig cochlear nucleus. Hear Res 174:264-280.

Mulders WH, Paolini AG, Needham K, Robertson D (2003) Olivocochlear collaterals evoke excitatory effects in onset neurones of the rat cochlear nucleus. Hear Res 176:113-121.

Mulders WH, Harvey AR, Robertson D (2007) Electrically evoked responses in onset chopper neurons in guinea pig cochlear nucleus. J Neurophysiol 97:3288-3297.

Mulders WH, Seluakumaran K, Robertson D (2008) Effects of centrifugal 
pathways on responses of cochlear nucleus neurons to signals in noise. Eur J Neurosci 27:702-714.

Mulders WH, Paolini AG, Needham K, Robertson D (2009) Synaptic responses in cochlear nucleus neurons evoked by activation of the olivocochlear system. Hear Res 256:85-92.

Neuert V, Verhey JL, Winter IM (2004) Responses of dorsal cochlear nucleus neurons to signals in the presence of modulated maskers. J Neurosci 24:5789-5797.

Norena A, Micheyl C, Chéry-Croze S, Collet L (2002) Psychoacoustic characterization of the tinnitus spectrum: implications for the underlying mechanisms of tinnitus. Audiol Neurootol 7:358-369.

Rajan R (1988) Effect of electrical stimulation of the crossed olivocochlear bundle on temporary threshold shifts in auditory sensitivity. I. Dependence on electrical stimulation parameters. J Neurophysiol 60:549-568.

Roberts LE, Moffat G, Baumann M, Ward LM, Bosnyak DJ (2008) Residual inhibition functions overlap tinnitus spectra and the region of auditory threshold shift. J Assoc Res Otolaryngol 9:417-435.

Robertson D, Gummer M (1985) Physiological and morphological characterization of efferent neurones in the guinea pig cochlea. Hear Res 20:63-77.

Robertson D, Winter IM (1988) Cochlear nucleus inputs to olivocochlear neurones revealed by combined anterograde and retrograde labelling in the guinea pig. Brain Res 462:47-55.

Sayles M, Winter IM (2008) Reverberation challenges the temporal representation of the pitch of complex sounds. Neuron 58:789-801.

Schofield BR, Cant NB (1996) Origins and targets of commissural connections between the cochlear nuclei in guinea pigs. J Comp Neurol 375:128-146.

Seki S, Eggermont JJ (2003) Changes in spontaneous firing rate and neural synchrony in cat primary auditory cortex after localized tone-induced hearing loss. Hear Res 180:28-38.

Seluakumaran K, Mulders WH, Robertson D (2008) Effects of medial olivocochlear efferent stimulation on the activity of neurons in the auditory midbrain. Exp Brain Res 186:161-174.

Sewell WF (1984) The relation between the endocochlear potential and spontaneous activity in auditory nerve fibres of the cat. J Physiol 347:685-696.

Shore SE, Sumner CJ, Bledsoe SC, Lu J (2003) Effects of contralateral sound stimulation on unit activity of ventral cochlear nucleus neurons. Exp Brain Res 153:427-435.

Smith PH, Massie A, Joris PX (2005) Acoustic stria: anatomy of physiolog- ically characterized cells and their axonal projection patterns. J Comp Neurol 482:349-371.

Starr A, Wernick JS (1968) Olivocochlear bundle stimulation: effects on spontaneous and tone-evoked activities of single units in cat cochlear nucleus. J Neurophysiol 31:549-564.

Thompson AM, Thompson GC (1991) Posteroventral cochlear nucleus projections to olivocochlear neurons. J Comp Neurol 303:267-285.

Torterolo P, Falconi A, Morales-Cobas G, Velluti RA (2002) Inferior colliculus unitary activity in wakefulness, sleep and under barbiturates. Brain Res 935:9-15.

Verhey JL, Pressnitzer D, Winter IM (2003) The psychophysics and physiology of comodulation masking release. Exp Brain Res 153:405-417.

Vernon JA, Meikle MB (2003) Tinnitus: clinical measurement. Otolaryngol Clin North Am 36:293-305, vi.

Vetter DE, Liberman MC, Mann J, Barhanin J, Boulter J, Brown MC, SaffioteKolman J, Heinemann SF, Elgoyhen AB (1999) Role of alpha9 nicotinic ACh receptor subunits in the development and function of cochlear efferent innervation. Neuron 23:93-103.

Wang J, Salvi RJ, Powers N (1996) Plasticity of response properties of inferior colliculus neurons following acute cochlear damage. J Neurophysiol 75:171-183.

Wang J, Ding D, Salvi RJ (2002) Functional reorganization in chinchilla inferior colliculus associated with chronic and acute cochlear damage. Hear Res 168:238-249.

Warr WB, Guinan JJ Jr (1979) Efferent innervation of the organ of Corti: two separate systems. Brain Res 173:152-155.

Warr WB, Boche JB, Neely ST (1997) Efferent innervation of the inner hair cell region: origins and terminations of two lateral olivocochlear systems. Hear Res 108:89-111.

Warr WB, Beck Boche JE, Ye Y, Kim DO (2002) Organization of olivocochlear neurons in the cat studied with the retrograde tracer cholera toxin-B. J Assoc Res Otolaryngol 3:457-478.

White JS, Warr WB (1983) The dual origins of the olivocochlear bundle in the albino rat. J Comp Neurol 219:203-214.

Wiederhold ML, Kiang NY (1970) Effects of electric stimulation of the crossed olivocochlear bundle on single auditory-nerve fibers in the cat. J Acoust Soc Am 48:950-965.

Winter IM, Robertson D, Cole KS (1989) Descending projections from auditory brainstem nuclei to the cochlea and cochlear nucleus of the guinea pig. J Comp Neurol 280:143-157. 